\title{
Survey on understanding after anesthetic induction simulation training in medical students' anesthesiology practice
}

\author{
Ji Seon Jeong ${ }^{1}$, Joo-Won Cho ${ }^{1}$, Tae Ho Lim², and Mi Ae Jeong ${ }^{1}$ \\ Departments of ${ }^{1}$ Anesthesiology and Pain Medicine, ${ }^{2}$ Emergency Medicine, Hanyang University College of Medicine, Seoul, Korea
}

Simulation originated from the field of aviation in 1929, it has been used not only in the aviation field but also in nuclear fuel industry for training, assessment, research and development, and its strength in this field was clearly demonstrated $[1,2]$. The anesthesia environment in the operating room and the aviation environment have a lot in common, such as simultaneous handling of several types of work, need for full attention when performing techniques, monitoring, critical thinking, and mutual cooperation with the operating team, etc. so it's fit to apply simulation in the operating room [1]. Simulation has been used in earliest in anesthesiology education as compared to other medical areas, and is diversely being used $[3,4]$. As yet, there no case of full scale computer simulation has been applied to anesthesiology medical students in Korea. We applied case simulation to 43 medical students using full scale computer simulation then investigated whether such a simulation could increase the understanding of anesthesiology education through questionnaires after its application. Before performing simulation practice, basic information was provided about the patient on the monitor as follows: The patient was male $170 \mathrm{~cm}$ in height, and $70 \mathrm{~kg}$ in weight, belonging to American Society of Anesthesiologists physical status classification 1, and he visited the hospital in order to get open reduction and internal fixation procedure due to a right distal radius facture from a recent fall. The patient did not have a specific medical history, nor did he take drugs at ordinary times. He fasted more than 8 hours.

In stage 1, an induction of general anesthesia was performed, and in stage 2 , an induction of anesthesia was performed for a patient with complications (such as: bronchial intubation, esophageal intubation, failed drug injection, pain during drug injection, hypertension, coughing during mask ventilation). All 43 students performed the same scenario in stage 1 . In addition, 29 of 43 students performed the stage 2 situation. At the simulation start time, this study identified the patient and linked the monitoring device to the mannequin, and according to the order of link, readings, electrocardiography (ECG), blood pressure (BP), pulse oximetry $\left(\mathrm{SpO}_{2}\right)$, end tidal carbon dioxide $\left(\mathrm{ETCO}_{2}\right)$, would appear on the monitor. Students gave the drugs of their choice to be used at the time of anesthesia induction. This study was performed by dividing each team into 2 groups (2-3 persons each) per team, and each member of the group played the role of the anesthesiologist, nurse, and observer for this simulation practice. About 10-15 minutes were required per scenario, and each group individually performed the scenarios three times by switching their role. A 5-10 minute debriefing while looking at the recorded video after each group finished practice was performed.

One month after all process of practice was done, this study conducted a questionnaire on the self-developed items. This study got students to respond to the questionnaire survey by counting the change in their understanding of anesthesia after and before simulation practice based on a 10-point scale for themselves. In addition, this study conducted an evaluation of the items on their understanding of the anesthesia drug, monitoring and anesthesia equipment, their confidence to approach the anesthesia patient after simulation practice, and the appropriateness and necessity of simulation practice, and the utility of debriefing after simulation based on a 5-point

Corresponding author: Mi Ae Jeong, M.D., Ph.D., Department of Anesthesiology and Pain Medicine, Hanyang University College of Medicine, 17, Haengdang-dong, Seongdong-gu, Seoul 133-791, Korea. Tel: 82-2-2290-8680, Fax: 82-2-2299-8692, E-mail: macheong@hanyang.ac.kr (c) This is an open-access article distributed under the terms of the Creative Commons Attribution Non-Commercial License (http:// creativecommons.org/licenses/by-nc/3.0/), which permits unrestricted non-commercial use, distribution, and reproduction in any medium, provided the original work is properly cited. 
Table 1. Questionnaire Survey

\begin{tabular}{|c|c|c|c|c|c|c|}
\hline $\begin{array}{l}\text { Questionnaire? } \\
\text { (Answered No. of students/Total No. of students) }\end{array}$ & $\begin{array}{l}\text { Strongly } \\
\text { agree }\end{array}$ & Agree & $\begin{array}{c}\text { Neither agree } \\
\text { nor disagree }\end{array}$ & Disagree & $\begin{array}{l}\text { Strongly } \\
\text { disagree }\end{array}$ & No answer \\
\hline $\begin{array}{l}\text { Do you think your understanding of anesthesia drug, } \\
\text { equipment and monitoring were increased through } \\
\text { simulation practice? }\end{array}$ & $8 / 43$ & $26 / 43$ & $8 / 43$ & $1 / 43$ & $0 / 43$ & $0 / 43$ \\
\hline $\begin{array}{l}\text { Do you feel more confident when approaching an } \\
\text { anesthesia patient? }\end{array}$ & $6 / 43$ & $23 / 43$ & $14 / 43$ & $0 / 43$ & $0 / 43$ & $0 / 43$ \\
\hline $\begin{array}{l}\text { Was the simulation class on the induction of anesthesia } \\
\text { appropriate for the students? }\end{array}$ & $6 / 43$ & $27 / 43$ & $8 / 43$ & $2 / 43$ & $0 / 43$ & $0 / 43$ \\
\hline $\begin{array}{l}\text { Was the simulation class on the induction of anesthesia } \\
\text { with complicationsappropriate for the students? }\end{array}$ & $4 / 29$ & $22 / 29$ & $1 / 29$ & $1 / 29$ & $0 / 29$ & $1 / 29$ \\
\hline Do your juniors need simulation practice? & $20 / 43$ & $16 / 43$ & $7 / 43$ & $0 / 43$ & $0 / 43$ & $0 / 43$ \\
\hline $\begin{array}{l}\text { Do you agree with the need to debrief after a } \\
\text { simulation? }\end{array}$ & $12 / 43$ & $22 / 43$ & $8 / 43$ & $1 / 43$ & $0 / 43$ & $0 / 43$ \\
\hline
\end{tabular}

Values are responded number of students. The survey was in Korean at the first research and it was translated in English in the process of writing ti into an essay.

Likert scale. The results are shown in Table 1.

When the student-evaluated changes in the understanding of anesthesia before and after simulation practice were compared on a 10-point scale, students' changes went upward significantly from $4.34( \pm 2.05)$ before practice to $7.79( \pm 1.39)$ after practice.

According to this study, it is judged that medical students heightened their understanding of the anesthesiology unit through full-scale simulation and it gave them confidence in the analysis of monitoring results, and approaching a patient. This study didn't focus on comparing the group who underwent simulation and the other group who didn't, and instead, it investigated a subjective students' ideas of the understanding of their level of anesthesiology, the appropriateness of scenarios and debriefing, and confidence in patients, etc. in the form of scores. Therefore, we cannot confirm what degree the effect of the simulation education in reality. However, the authors believe that simulation education in the specialty of anesthesia was helpful to arouse the interests from students. We also think that such an arousal of interest will help enhance the understanding of anesthesia and contribute to increasing their confidence to treat patients.

We hope that simulation education in the anesthesiology specialty in Korea, which is still staying at an early stage, could be a motive for developing more educational programs and evaluation tools. In addition, we hope that there could be active development and application of simulation concerning crisis resource management for not only medical students but also residents in the future

\section{References}

1. Wong AK. Full scale computer simulators in anesthesia training and evaluation. Can J Anaesth 2004; 51: 455-64.

2. Cumin D, Weller JM, Henderson K, Merry AF. Standards for simulation in anaesthesia: creating confidence in the tools. $\mathrm{Br} \mathrm{J}$ Anaesth 2010; 105: 45-51.

3. Farnsworth ST, Egan TD, Johnson SE, Westenskow D. Teaching sedation and analgesia with simulation. J Clin Monit Comput 2000; 16: 273-85.

4. Dalley P, Robinson B, Weller J, Caldwell C. The use of high-fidelity human patient simulation and the introduction of new anesthesia delivery systems. Anesth Analg 2004; 99: 1737-41. 